\title{
Ensinando/aprendendo sobre mapas conceituais - convite ao uso de um manual como orientador de práticas pedagógicas
}

\section{Teaching / learning about concept maps - invitation to the use of a manual supervisor educational practices}

\author{
${ }^{1}$ Stella Maria Maffra stella.maffra@terra.com.br \\ ${ }^{2}$ Maylta Brandão dos Anjos
}

\section{RESUMO}

A pesquisa trata da feitura do produto educacional de um mestrado profissional no Estado do Rio de Janeiro. O objetivo da pesquisa foi proceder um trabalho com os mapas conceituais,a partir de um manual que foi confeccionado durante o processo da pesquisa e foi utilizado como mais um apoio para práticas pedagógicas, por possuir noções dos fundamentos teóricos ligados aos mapas conceituais e, por trabalhar algumas estratégias de utilização com dicas e exemplos dos mapas. A partir de uma metodologia participante, a contribuição dos sujeitos da pesquisa se deu e, o manual foi construído no aprendizado das regras de construção, elaboração e a aplicação de atividades que prescindem da utilização de computadores e/ou softwares para sua realização, bastou para tal, lápis e papel e a dinâmica do corpo a corpo que imperou na sala de aula. Como resultado, a compreensão dos fundamentos e das práticas contidas no produto final vislumbrou a versatilidade do instrumento confeccionado e aplicado, uma vez que pode ser utilizado como instrumento didático-pedagógico no ensino de qualquer disciplina, tanto para o reforço da compreensão quanto para a verificação da aprendizagem, além de funcionar muito bem para a identificação de conceitos mal compreendidos. Concluímos que as novas metodologias propostas devem ser capazes de aperfeiçoar o ato de ensinar em um constante enriquecimento de sua ação pedagógica ao mesmo tempo, em que possa incentivar ao aluno, a capacidade de se tornar um partícipe ativo de seu processo de aprendizagem, enriquecendo os elementos de sua autonomia, empoderamento e participação da educação no mundo.

Palavras-chave: Mapas conceituais. Ensino-aprendizagem. Práticas pedagógicas.

\begin{abstract}
The research deals with the making of the educational product of a professional master in the State of Rio de Janeiro. The objective was to conduct a study with the conceptual maps, from a manual that was made during the research process and was used as an additional support for teaching practices, to possess notions of the theoretical foundations linked to conceptual maps, and work some use strategies with tips and examples of maps. From a participant methodology, the contribution of the research subjects was, and the manual was built in learning the rules of construction, development and implementation of activities that necessitate the use of computers and / or software for its realization, it was enough to such, pencil and paper and body dynamics of the body that existed in the classroom. As a result, understanding the fundamentals and practices contained in the final product envisioned the versatility made and applied instrument, since it can be used as didactic and pedagogical tool in teaching any subject, both for strengthening understanding and for checking learning, and work very well for identifying misunderstood concepts. We conclude that the proposed new methodologies to be able to perfect the act of teaching in a constant enrichment of their pedagogical action at the same time, they can encourage the student the ability to become an active participant in the learning process, enriching the elements of its autonomy, empowerment and participation of education in the world.
\end{abstract}

Keywords: Conceptual maps. Teaching and learning. Pedagogical practices.

1 Mestre em Ensino de Ciências/IFRJ- Campus Nilópolis

2 Instituto Federal de Educação, Ciência e Tecnologia do Rio de Janeiro, Campus Nilópolis (IFRJ)/PROPEC 


\section{INTRODUÇÃO}

Os Mestrados Profissionais em Ensino de Ciência, geralmente, propõem o desenvolvimento de um produto educacional capaz de agregar novos recursos às práticas educacionais. Este artigo pretende descrever alguns pontos importantes para a utilização dos Mapas Conceituais, como ferramenta geradora, através do uso do Manual Ensinando/Aprendendo sobre Mapas Conceituais, desenvolvido a partir da aplicação das estratégias relacionadas à pesquisa durante a construção de um produto educacional de um curso de Mestrado Profissional.

De modo geral, percebemos na atividade docente, a necessidade de atuações didáticas e estratégias de ensino mobilizadoras das competências dos alunos, favorecendo a construção do conhecimento e a formação de um olhar crítico-reflexivo contribuindo assim, para a melhoria da educação. Mas verificamos também que, para a utilização de qualquer recurso mediador da aprendizagem, é fundamental saber utilizar a ferramenta escolhida e, ser capaz de planejar atividades e estratégias de ensino adequadas ao seu uso.

Como, ao longo de nossa pesquisa de Mestrado, verificamos que o mapa conceitual pode ser enquadrado como uma ferramenta pedagógica capaz de favorecer um ensino mais significativo e prazeroso e que, suas estratégias permitem gerar expressivas mudanças nas atividades educacionais contribuindo na construção de situações de aprendizagem dinâmicas, colaborativas e integradas, desenvolvemos um produto educativo voltado para a utilização mais eficiente desta ferramenta.

Assim, ao elaborarmos o citado manual, foram apresentados os embasamentos teóricos mais relevantes e algumas formas de utilização dos mapas conceituais através de diversas estratégias previamente testadas. Deste modo, as etapas da construção do manual visaram proporcionar ao professor um aprendizado fácil, rápido e seguro do uso dos Mapas Conceituais como recurso didático/pedagógico, elaborando um conjunto de recursos para que os alunos pudessem dominar o uso desta técnica de estudo/aprendizado com relativa facilidade. Portanto, este manual traz em sua intencionalidade o aprendizado da utilização dos Mapas Conceituais.

\section{DESCREVENDO O MANUAL}

O Manual Ensinando/Aprendendo sobre Mapas Conceituais vem apresentando noções dos fundamentos teóricos, algumas estratégias de utilização, dicas e exemplos de mapas conceituais, como mecanismo ilustrativo das diversas possibilidades de utilização que este recurso oferece. Focamos no aprendizado das regras de construção, elaboração e a aplicação dos mapas conceituais de tal modo que seja possível utilizá-lo com maior propriedade conceitual para utilização no dia a dia dos professores e alunos.

As atividades descritas no manual podem ser utilizadas durante a prática pedagógica e nos estudos em casa e, prescindem da utilização de computadores e/ou softwares para sua realização, bastando para tal, lápis e papel.

Ao avançarmos pelos conhecimentos relativos à construção dos mapas conceituais dentro do manual, logo se percebe que a compreensão dos fundamentos para esta ferramenta e seu uso adequado, leva a vislumbrar a versatilidade do instrumento uma vez que pode ser utilizado como instrumento didático-pedagógico no ensino de qualquer disciplina, tanto para o reforço da compreensão quanto para a verificação da aprendizagem, além de funcionar muito bem para a identificação dos conceitos mal compreendidos.

O manual, de forma simples, demonstra que o mapa conceitual pode ser usado em diversas situações e com diferentes finalidades, como uma ferramenta poderosa e profunda, que permite captura, representação e arquivamento do conhecimento, bem como a criação de novos conhecimentos e, deste modo, gerando uma aprendizagem significativa capaz de auxiliar o aprendizado acadêmico e o trabalho do professor em suas aulas, uma vez que torna visualmente mais clara a tarefa de explicitar informações e apontar caminhos. 
Para atingir os objetivos propostos, nosso manual apresenta figuras e uma linguagem agradável, onde convidamos o aprendiz a "participar desta aventura rumo aos mapas conceituais, trazendo para sua vida, a aprendizagem através deste fantástico recurso pedagógico dinâmico e instigante” (MAFFRA, 2011, p.02) enquanto mostramos toda a versatilidade da ferramenta como recurso não só para detectar o que foi aprendido, como também identificar o que não foi e as dificuldades enfrentadas pelo aprendiz. E, lembramos sempre que, durante a criação, reestruturação e análise de mapas conceituais, todos ficarão envolvidos no processo criativo levando assim a uma aprendizagem significativa.

Através de perguntas estrategicamente apresentadas, como na figura 1, buscamos aguçar a curiosidade e a reflexão para, em seguida, oferecermos a resposta capaz de levar ao entendimento, que segue acompanhado de um aprofundamento teórico sobre a questão.

\section{Figura 1 - Perguntas estrategicamente apresentadas}

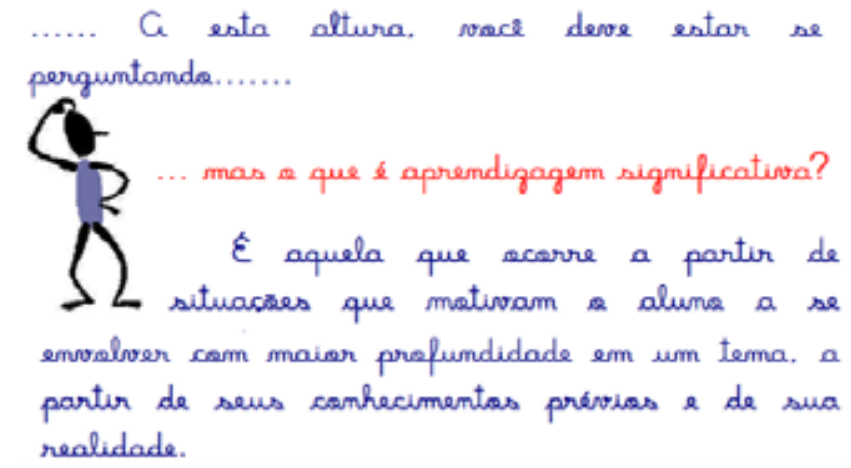

Fonte: Manual Ensinando/Aprendendo sobre Mapas Conceituais (MAFFRA, 2011, p.04).

Ao longo destes pequenos, mas relevantes aprofundamentos teóricos, outros conceitos fundamentais vão sendo inseridos através de novas indagações (figura 2), novas respostas e novas temáticas de modo que, todo o embasamento teórico vai sendo construído de forma gradual, instigante e agradável, estruturando uma rede significativa com os conhecimentos necessários para o uso do mapa conceitual como estratégia no ensino-aprendizagem.

\section{Figura 2 - Novas indagações}

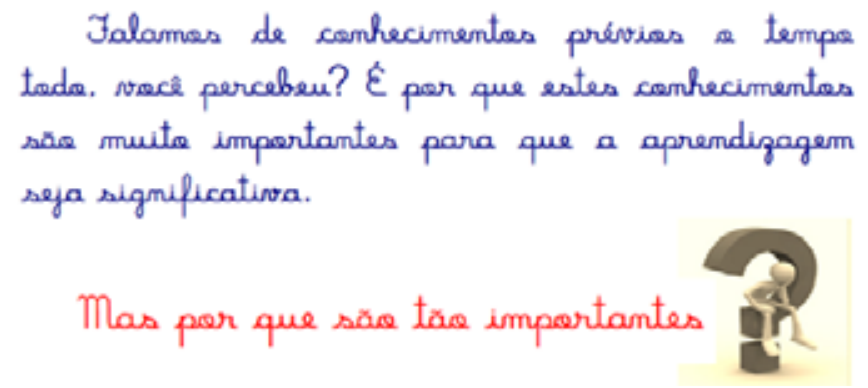

Fonte: Manual Ensinando/Aprendendo sobre Mapas Conceituais (MAFFRA, 2011, p.06).

Como lidamos com um manual estruturado por pesquisa durante a prática do Mestrado, e apresentamos um conteúdo relevante e apropriado ao aprendizado do uso de Mapas Conceituais, ele não poderia prescindir das referências dos autores mais proeminentes dentro da temática. Balizando nossas colocações ao longo dos textos, conceitos e imagens, vamos apresentando os nomes (figura 3) mais relevantes dos autores nacionais e internacionais, acompanhados das respectivas referências bibliográficas. 
Figura 3 - Referência de Autor

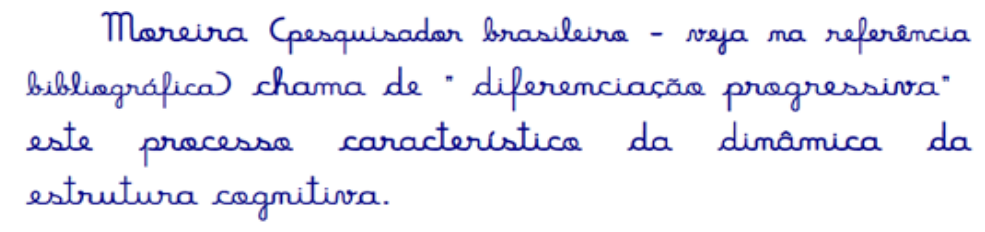

Fonte: Manual Ensinando/Aprendendo sobre Mapas Conceituais (MAFFRA, 2011, p.06).

Até aqui, conceitos fundamentais para o entendimento da ferramenta, como aprendizagem significativa, conhecimentos prévios e mapas conceituais foram apresentados e, para que o conteúdo do Manual permaneça interessante e não haja uma perda do foco, que é ensinar/aprender a utilizar Mapas Conceituais, todas as demais elaborações teóricas vão sendo repassadas enquanto o aprendiz é convidado a embarcar na aventura de aprender a construir os Mapas Conceituais propriamente ditos.

Ressaltamos a importância dos conhecimentos prévios sobre o assunto a ser estudado/aprendido por meio dos Mapas Conceituais e endereçamos este lembrete tanto aos professores quanto aos alunos, de modo que todos saibam que é necessário buscar tais referências conceituais dizendo que

se você é professor, vai precisar orientar os alunos na pesquisa e seleção de informações sobre um conteúdo específico através da leitura de textos em livros, jornais, revistas, sites etc. Se você está estudando sozinho ou com seus colegas, precisa buscar algumas informações preliminares sobre o assunto a ser trabalhado. (MAFFRA, 2011, p.09)

Estruturamos em seguida, as etapas fundamentais para a construção dos Mapas Conceituais, tais como: aquisição de conhecimentos prévios e formulação de um questionamento sobre o tema através da elaboração de uma questão de foco. Sempre apresentando informações rápidas e fáceis para o entendimento dos novos conceitos apresentados e também, para relembrar os conceitos aprendidos anteriormente.

O trabalho com os Mapas Conceituais ajuda a vencer uma das maiores dificuldades (percebida por nossa pesquisa) durante o ensinar/aprender, que é ser capaz de detectar os conceitos relevantes e o foco central de um texto. Na tentativa de vencer esta tendência, o Manual busca explicitar que os mapas conceituais visam relacionar e hierarquizar conceitos e desafia o aprendiz a primeiramente identificar no texto com o qual está trabalhando, os conceitos-chave, separá-los em mais abrangentes e menos inclusivos, para, em seguida, hierarquizar estes conceitos, organizando-os dos mais gerais aos mais específicos de modo a integrá-los numa rede de relações através de linhas acrescidas de significados.

Assim, através de figuras e novas informações, o aprendiz é levado a construir um mapa conceitual que, segundo Boeres et al (2006, p. 02), tem como elementos de composição conceitos e as relações existentes entre estes conceitos, dispostos em uma linguagem gráfica, onde um conceito é representado por uma figura geométrica (usualmente retângulos) e, uma relação entre dois conceitos, é representada por um segmento de reta que liga as figuras geométricas que os representam. $\mathrm{O}$ aprendiz então começa a consolidar a ideia de que - a cada conceito e a cada relação está associada uma palavra ou frase - usada para descrever a semântica do conceito ou relação, conforme a figura 4 demonstra de forma inicial e simplificada. 
Figura 4 - Mapa Conceitual: Relações entre Conceitos

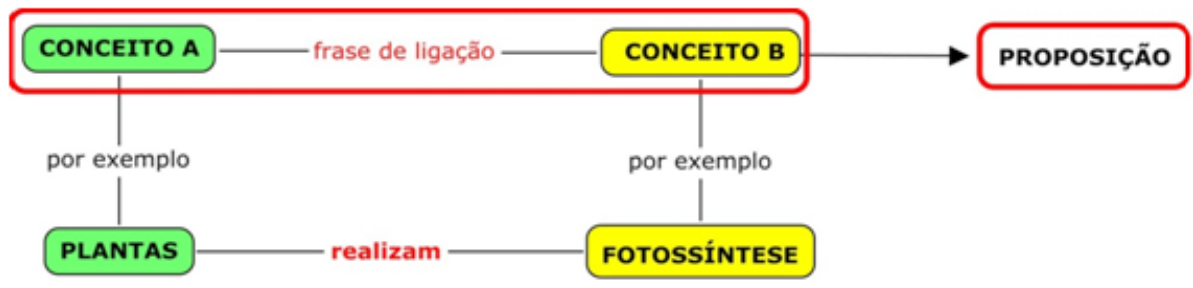

Fonte: Manual Ensinando/Aprendendo sobre Mapas Conceituais (MAFFRA, 2011, p.11).

Através desta representação gráfica bidimensional simples o aluno terá a chance de perceber que no Mapa Conceitual visualizamos um conjunto de conceitos (retângulos) que devem ser organizados de modo a evidenciar as relações existentes entre eles por meio de pequenas frases de ligações representadas por linhas conectando os conceitos.

O Manual permite verificar, com certa facilidade, que "esta representação conceito + frase de ligação + conceito, é denominada proposição” (MOREIRA, 1997, p.02), ou seja, frases que refletem as relações conceituais e acrescenta em seguida, um outro exemplo elaborado utilizando o Cmaptools (figura 5), um programa criado por Novak (2006, p.14) para construção de mapas conceituais, de modo a instigar a curiosidade do aprendiz para mais esta novidade.

Figura 5 - Mapa conceitual demonstrando conceitos e frases de ligação

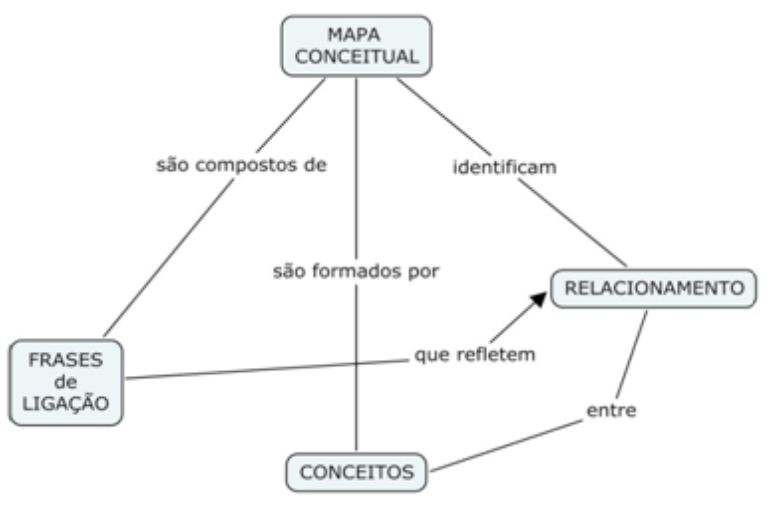

Fonte: Manual Ensinando/Aprendendo sobre Mapas Conceituais (MAFFRA, 2011, p.12).

Para recapitular tudo até então ensinado/aprendido e, dar ao aluno a sensação de segurança de que seus conhecimentos podem chegar a um denominador comum, apresentamos um resumo (figura 6) de tudo que precisamos para a elaboração de um mapa conceitual. 
Figura 6 - Etapas

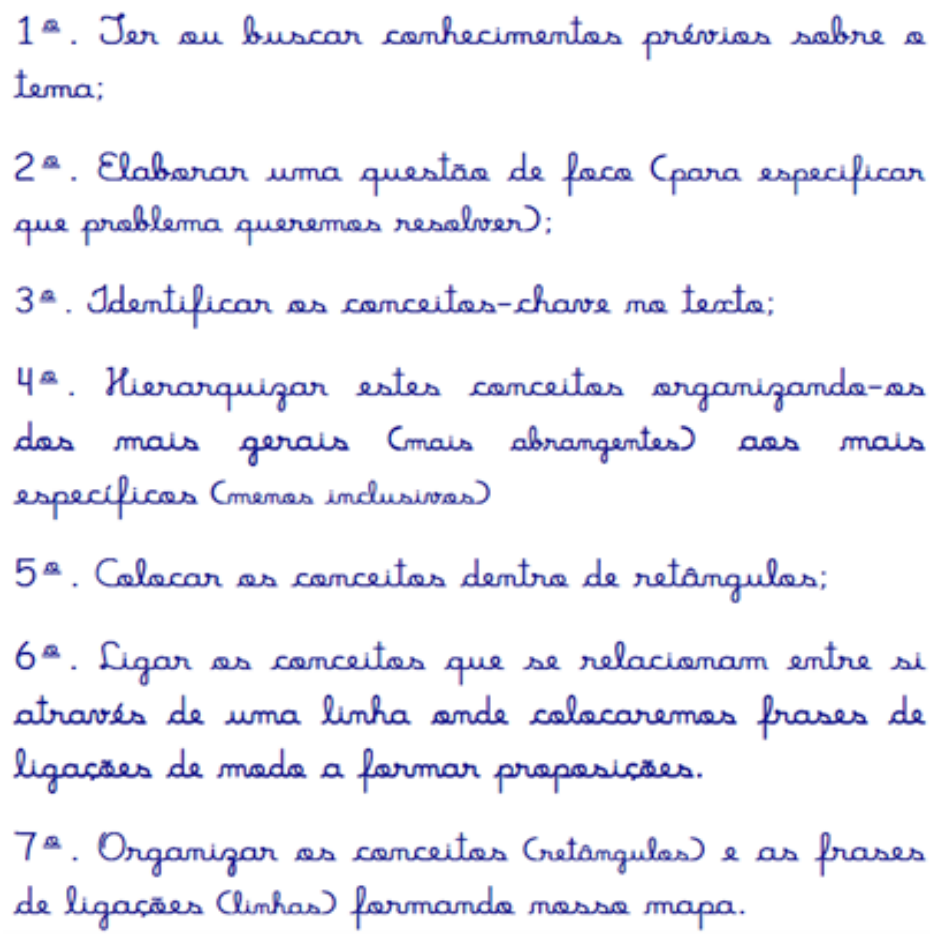

Fonte: Manual Ensinando/Aprendendo sobre Mapas Conceituais (MAFFRA, 2011, p.13).

Nesse momento se faz importante instruir o aprendiz na prática, para que ele possa entender toda a dinâmica de construção das etapas listadas na figura 6, a título de ilustração do passo a passo para a elaboração de um Mapa Conceitual. Para tanto, nosso Manual utiliza um texto aonde vamos demonstrando como encontrar a preocupação central do mesmo, como formular uma questão de foco adequada a ele, sublinhamos os conceitos-chave, apontamos quais destes conceitos são mais ou menos abrangentes e solicitamos ao aprendiz a construção de uma lista colocando em ordem decrescente de inclusão os conceitos listados enquanto apresentamos alguns exemplos. Propomos, então, a colocação dos conceitos dentro de retângulos, a união, através de linhas, dos conceitos que se relacionam uns com os outros e, construímos um Mapa Conceitual com todas as informações.

Deixamos sempre claro ao aprendiz (figura 7) através de outros exemplos, que ele poderia formular outra questão de foco e sublinhar outros ou mais conceitos - uma vez que todas estas escolhas dependem - sempre, do conhecimento prévio, que cada um carrega a respeito do assunto e da relação pessoal com o texto. Em se tratando da construção de Mapas Conceituais, é muito importante que se mantenha em mente, professor e alunos que, se o mapa depende dos conhecimentos prévios de cada um sobre o tema e das escolhas pessoais em relação ao material proposto, ele será um mapa conceitual e não o mapa conceitual, quer dizer, cada mapa é único e por isso mesmo, deve ser explicado por quem o fez, pois ao explicá-lo, a pessoa vai externalizar os significados percebidos por ela (MOREIRA,1997). 
Figura 7 - Escolhas

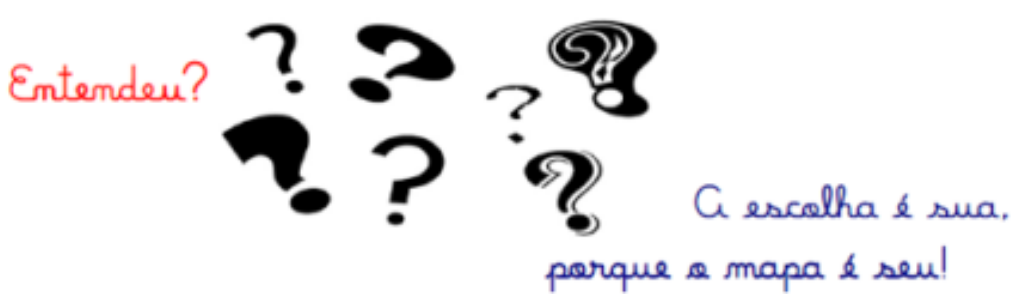

Fonte: Manual Ensinando/Aprendendo sobre Mapas Conceituais (MAFFRA, 2011, p.16).

Aos poucos, apresentamos as informações pertinentes à utilização dos Mapas Conceituais como ferramenta de aprendizagem, enquanto sutilmente, vamos aprofundando conceitos, ampliando conhecimentos e introduzindo questões mais complexas como a visão de Moreira (2006, p.10) que propõe, "uma hierarquia vertical, de cima para baixo, indicando relações de subordinação entre conceitos" onde "conceitos com aproximadamente o mesmo nível de generalidade e inclusividade aparecem na mesma posição vertical.”

Esta visão permite ao aprendiz verificar a existência de uma "dimensão horizontal” no mapa conceitual pelo fato de que vários conceitos podem aparecer em uma mesma posição vertical como demonstrado na figura 8. Veja que, agregar esta nova informação no momento certo, gera a possibilidade de construção de mapas mais elaborados, sem, contudo, assustar o aprendiz provocando resistência pela maior grau de dificuldade acrescentado ao aprendizado.

Figura 8 - Dimensão vertical e horizontal de um mapa conceitual.

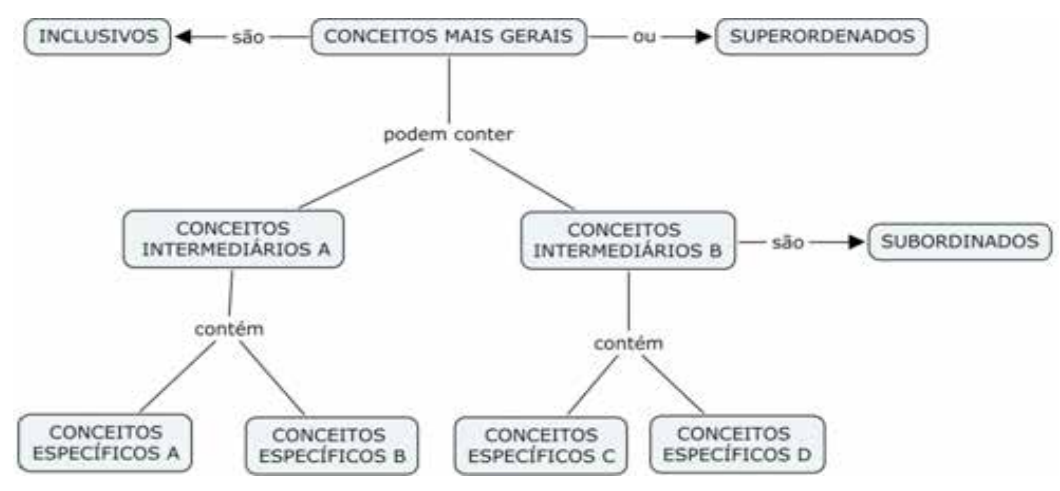

Fonte: Manual Ensinando/Aprendendo sobre Mapas Conceituais (MAFFRA, 2011, p.19).

Para alguns autores, o foco maior é a frase de ligação que precisa ser bem construída onde, para começar, poucas e bem delimitadas etapas para a construção dos Mapas Conceituais seriam suficientes, como no caso de Dutra (2005, p. 35) nos lembrando que uma característica importante dos mapas é a "frase de ligação que deve sempre conter verbos conjugados de acordo com o sentido que se quer dar à proposição.” Este autor sugere quatro etapas principais para construção de um mapa conceitual, onde - o ato de escolher um par de conceitos para estabelecimento da(s) relação(ões) entre eles e a construção da frase de ligação para esse par de conceitos escolhido - se repetem tantas vezes quanto necessário.

Através do manual, estas nuances ficam explicitadas de modo muito claro como na figura 9, assinalando durante a dinâmica do aprendizado que, depois que um mapa conceitual preliminar é construído pelo aprendiz, ele deve procurar as ligações existentes entre os diferentes conceitos vislumbrando possibilidades de modificações e reconstrução de seu Mapa Conceitual. 
Figura 9 - Possibilidades

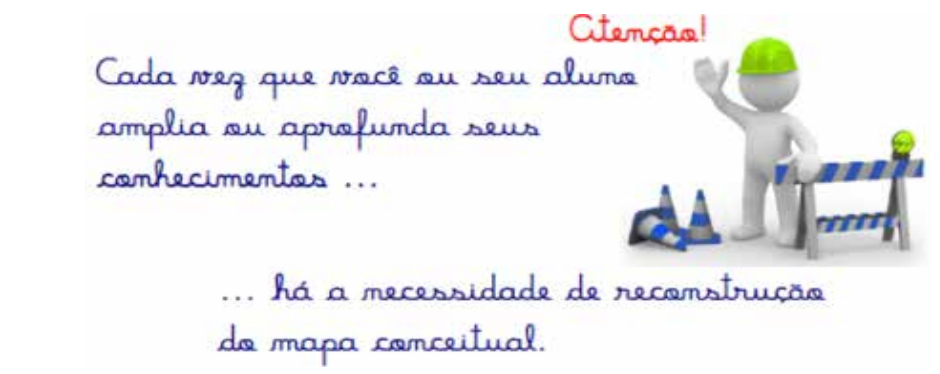

Fonte: Manual Ensinando/Aprendendo sobre Mapas Conceituais (MAFFRA, 2011, p.20).

Aos poucos, através de exemplos, vamos acrescentando informações que propiciam a construção de Mapas Conceituais cada vez mais elaborados, através da introdução de novos elementos como: a utilização de setas, a inclusão de ligações cruzadas (Crosslinks, linhas tracejadas- fig.10) propostas por Novak (2006, p.02) e que refletem os relacionamentos ou ligações entre conceitos em diferentes segmentos ou domínios do mapa conceitual.

Figura 10 - Mapa Conceitual sobre Informação Genética.

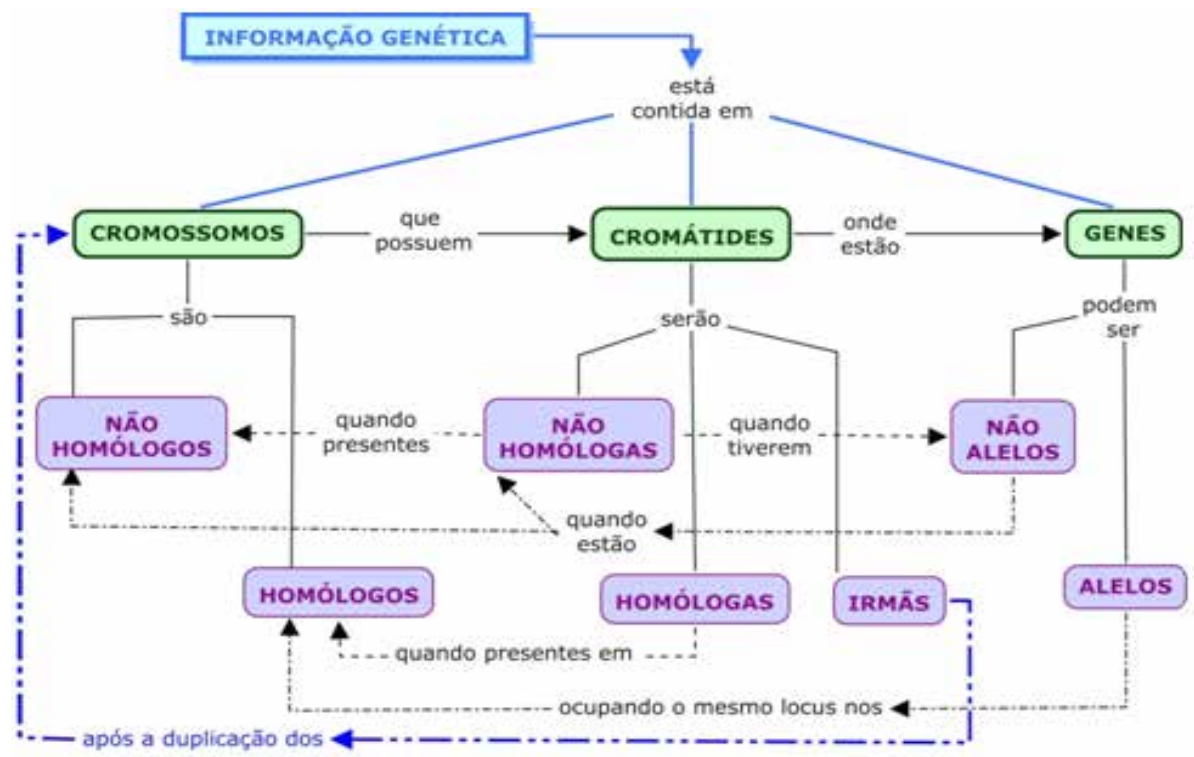

Fonte: Manual Ensinando/Aprendendo sobre Mapas Conceituais (MAFFRA, 2011, p.21).

Para que o aprendiz, seja ele professor ou aluno, possa ampliar a utilização dos Mapas Conceituais em suas práticas de ensino/aprendizagem, apresentamos diversos tipos de Mapas, suas principais características e as vantagens e desvantagens para a utilização de cada um deles, sempre acompanhados de exemplos visuais capazes de ampliar o entendimento.

Durante a construção do Manual Ensinando/Aprendendo Sobre Mapas Conceituais, após deixarmos o aprendiz bem familiarizado com a construção de Mapas Conceituais, verificamos ser importante apresentar as diversas formas com que podemos construir um mapa conceitual, de modo que, tanto professores quanto alunos, possam utilizar a ferramenta de acordo com sua realidade educacional, financeira e/ou vontade. Podemos usar lápis e/ou caneta e papel; figuras geométricas recortadas em cartolina, papel colorido ou e.v.a para montagem e também, através de softwares elaborados com esta finalidade. 
Para aqueles que dominam o uso dos computadores/internet, listamos os diferentes softwares disponíveis para a construção de Mapas Conceituais, apresentando seus respectivos endereços eletrônicos, mas aprofundamos as informações sobre o CmapTools, considerado um dos aplicativos mais úteis na construção de mapas conceituais, além de ser gratuito e em português.

Com o intuito de facilitar a busca de informações pertinentes à construção dos Mapas Conceituais e, para tornar tudo mais interessante, acrescentamos diversas dicas, endereços de sites, blogs e vídeos e exemplos de utilização de Mapas Conceituais nas mais variadas disciplinas. E, para ajudar o professor em seu fazer pedagógico diário, durante nossa pesquisa de mestrado, testamos a viabilidade de aplicação de algumas estratégias com a utilização de mapas conceituais para o ensino/estudo de qualquer disciplina, e adaptáveis a qualquer nível de escolaridade.

\section{Figura 11}

\section{Măe acredita?}

\section{Dê uma olhada...}

Fonte: Manual Ensinando/Aprendendo sobre Mapas Conceituais (MAFFRA, 2011, p.34).

Descrevemos, exemplificamos, damos dicas e criamos diversas tarefas diferentes para o professor aplicar em sua sala de aula, através de estratégias diversificadas e apresentadas de forma gradual e simples. Muitas destas tarefas permitem gerar uma construção colaborativa extremamente gratificante, pois os alunos precisarão negociar os conceitos e, suas respectivas relações, entre eles, provocando debate, e considerável ampliação dos conhecimentos de todos. O professor pode encontrar materiais como: $1^{\mathrm{a}}$. Ensinando/Aprendendo com Mapas Conceituais (*Estratégia: Conhecendo os Mapas Conceituais); 2a . Usando Mapas Conceituais Para Construção de Textos (*Estratégia: Construindo textos a partir de Mapas Conceituais); $3^{\text {a. }}$. Usando Mapas Conceituais Para Ancorar Novos Conhecimentos Adquiridos (*Estratégia: Hierarquizando conceitos com Mapas Conceituais e ancorando novos conhecimentos); $4^{\mathrm{a}}$. Revendo Conceitos (*Estratégia: Usando os Mapas Conceituais como Mecanismo de Revisão de Conteúdo); 5 a . Crosslinks (*Estratégia: Buscando referências cruzadas no Mapa Conceitual); 6a. Mapas Conceituais como Mecanismo de Integração (*Estratégia: Construção do Mapa Conceitual pela turma como uma equipe única)

Acreditamos que o Manual Ensinando/Aprendendo sobre Mapas Conceituais vem trazendo informações que permitam ao aprendiz utilizar os mapas conceituais como uma ferramenta para organizar seus estudos, construir resumos e tudo o mais que sua imaginação puder construir. E, no caso do professor, perceber neste recurso, uma forma de facilitar a construção dos seus planos de aulas e também, como um precioso mecanismo para tornar suas aulas mais produtivas e prazerosas, pois os Mapas Conceituais possibilitam a produção de interações motivadoras.

\section{CONSIDERAÇÕES FINAIS}

Na tentativa de valorização do ensino, espera-se do educador contemporâneo, a procura por novas metodologias capazes de aperfeiçoar o ato de ensinar em um constante enriquecimento de sua ação pedagógica ao mesmo tempo, em que exige do aluno, a capacidade de se tornar um partícipe ativo de seu processo de aprendizagem. 
Assim, constantemente buscamos recursos adequados de modo a tornar o ato de ensinar/aprender uma prática pedagógica capaz de gerar, uma aprendizagem efetiva e prazerosa para todos os envolvidos no processo. Existem muitas metodologias, muitas ferramentas e recursos capazes de propiciar tal enriquecimento educacional, embora nem sempre os envolvidos neste uso, apresentem o conhecimento e o domínio adequados.

A partir de toda a pesquisa realizada durante o Mestrado,

\begin{abstract}
Verificamos que o mapa conceitual pode ser enquadrado como uma ferramenta pedagógica capaz de favorecer um ensino mais significativo e prazeroso e que, suas estratégias permitem gerar expressivas mudanças nas atividades educacionais contribuindo na construção de situações de aprendizagem dinâmicas, colaborativas e integradas. (MAFFRA, 2011a, p.105/106)
\end{abstract}

Usar um Manual para apreender de forma rápida e consistente as informações necessárias à utilização de um recurso didático-pedagógico permite a construção de uma ferramenta, a partir da compilação dos elementos mais fundamentais para a utilização do recurso, vencendo assim a falta de tempo tão presente em nossas práticas cotidianas.

Partindo destas premissas, elaboramos o Manual Ensinando/Aprendendo Sobre Mapas Conceituais de modo a introduzir, paulatinamente, todos os conceitos fundamentais e o passo a passo para a utilização desta ferramenta, que verificamos ser capaz de auxiliar a aprendizagem acadêmica e o fazer pedagógico do professor no âmbito de sua rotina profissional.

A elaboração deste Manual exigiu apresentação de conceitos, fundamentos teóricos e regras de construção dos mapas conceituais, bem como desenvolver formas variadas de utilização dos Mapas Conceituais que pudessem ser aplicadas como mecanismo de estudo/ensino e, para tanto, durante nossa investigação, aplicamos, analisamos e desenvolvemos estratégias diferenciadas de aplicabilidade dos Mapas Conceituais.

Esperamos assim, colaborar com o professor em formação e/ou atuante, através da compilação de informações capazes de desenvolver as habilidades indispensáveis para o uso deste recurso no cotidiano escolar, oferecendo um conjunto previamente organizado de estratégias de modo a facilitar a aplicação dos mapas conceituais em sala de aula.

Convidamos nossos leitores, sejam estes alunos e/ou professores, a utilizar o Manual e suas fundamentações como um recurso de ensino/ aprendizado capaz de favorecer um ensino mais significativo e prazeroso. Confiamos que a utilização de suas estratégias pode gerar expressivas atividades educacionais e contribuir na construção de situações de aprendizagem dinâmicas, colaborativas e integradas. 


\section{REFERÊNCIAS}

BOERES, M. C. S., CURY, D., MENEZES, C. S. de, \& CARLESSO, G. Uma Abordagem para comparação de mapas conceituais utilizando correspondência de grafos. CINTED-UFRGS. Novas Tecnologias na Educação. RENOTE. V. 4. n ${ }^{\circ}$ 2. 2006. Disponível em: <http://seer.ufrgs.br/renote/article/view/14264>. Acesso em: Jan. 2016.

DUTRA, Í. M. Novas formas de aprender, novas formas de avaliar. Mapas conceituais e uma proposta de categorias construtivistas para seu uso na avaliação da aprendizagem. Um Salto Para O Futuro. Boletim 15. Pgm5. Agosto 2005. Disponível em: <http://www.pucrs.br/famat/viali/tic_literatura/artigos/blogs/NEVADO.pdf>. Acesso em: Jan. 2016.

MAFFRA, Stella Maria. O uso dos mapas conceituais como recurso didático pedagógico facilitador do processo de ensino aprendizagem. Monografia (Lato Sensu) Centro Federal de Educação Tecnológica Celso Suckow da Fonseca, 2010. Orientadora: Mônica de Cássia Vieira Waldhelm.

Mapas conceituais como recurso facilitador da aprendizagem significativa - uma abordagem prática. 129 f. Trabalho de conclusão em Ensino de Ciências/Dissertação. Programa de Pós-graduação Stricto Sensu, Instituto Federal de Educação, Ciência e Tecnologia do Rio de Janeiro (IFRJ), Campus Nilópolis, Nilópolis, RJ,

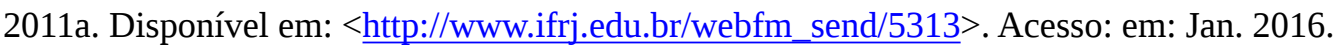

MANUAL. Ensinando/aprendendo sobre mapas conceituais. 2011. Disponível em: <http://www.ifrj.edu.br/webfm_send/3058>. Acesso: em: Jan. 2016.

MOREIRA, M. A. Mapas conceituais e aprendizagem significativa. 1997. Disponível em:

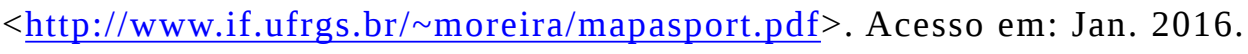

Mapas conceituais e diagramas V. Instituto de Física, UFRGS, 2006. Disponível em:

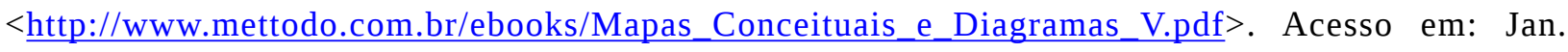
2016.

NOVAK, J.D. , A.J. CANÃS. The theory underlying concept maps and how to construct and use them. Florida Institute for Human and Machine Cognition.Pensacola Fl, 32502. Disponível em: <http://cmap.ihmc.us/ docs/theory-of-concept-maps>. Acesso em: Jan. 2016. 